\section{Levantamento etnobotânico das plantas medicinais do cerrado utilizadas pela população de Mossâmedes (GO)}

\author{
Vila Verde, G.M. ${ }^{\text {* }}$; Paula, J.R. ${ }^{\text {; }}$ Caneiro, D.M. ${ }^{2}$ \\ ${ }^{1}$ Laboratório de Farmacognosia - Faculdade de Farmácia / \\ UFG \\ ${ }^{2}$ Hospital de Medicina Alternativa - SES / GO
}

farmacológicos e fitoquímicos, por já estarem consagradas pelo uso contínuo ${ }^{3}$.

Nessa perspectiva, o trabalho é composto por um acervo de informações sobre a medicina popular da região de Mossâmedes. Fundada em 1774, a cidade está localizada a 150 quilômetros de Goiânia, capital de Goiás, e compreende parte da Reserva Biológica da Serra Dourada. A área representa uma das importantes remanescências de cerrado do estado, abarcando inclusive um centro de pesquisa da Universidade Federal de Goiás, localizado a $16^{\circ} 04^{\prime} 28.5^{\prime \prime}$ latitude sul e $50^{\circ} 11^{\prime} 13.6^{\prime \prime}$ longitude West Greenwich. A região possui cerca de 3600 habitantes, sendo a população composta por, dentre outros, descendentes de tribos indígenas, que já ocupavam a região por volta do ano de $1755^{4,5}$.

O presente trabalho teve como objetivo levantar as espécies nativas do cerrado, mais conhecidas e utilizadas pela população da cidade de Mossâmedes (GO), e avaliar a influência da proximidade da população à Reserva Biológica da Serra Dourada sobre esse conhecimento.

As plantas medicinais do cerrado, mais utilizadas estão apresentadas em ordem alfabética de seus respectivos nomes científicos, os nomes das famílias entre parênteses, seguidos da nomenclatura vulgar e breve notação sobre a forma de utilização, parte da planta utilizada e indicação terapêutica (tabela 1).

O trabalho realizado permitiu delinear superficialmente a relação existente entre a população da cidade de Mossâmedes (GO), a flora local e as tradições da medicina popular. Dos entrevistados, $57 \%$ utilizam algum tipo de planta medicinal e na maioria das vezes, plantas exóticas domesticadas como Rosmarinus officinalis L., Achyrocline satureioides D.C., Cymbopogon citratus (D.C.) Stapf., Mentha sp., Aloe vera (L.) Brum. f., Plectranthus barbatus Andr. e outras. Uma parcela de $80 \%$ dos entrevistados desconhece métodos de coleta ou cultivo de plantas nativas, ou seja, não houve permanência das tradições de reconhecimento e extrativismo da flora nativa. Em geral, a população faz uso das plantas medicinais por indicação dos raizeiros, que desenvolvem o extrativismo e comercialização, em pequena escala, das plantas nativas da região.

Portanto, a influência da proximidade da Reserva Biológica da Serra Dourada na etnomedicina de Mossâmedes é significativa quando analisado o aspecto de disponibilidade de plantas medicinais para utilização na terapêutica e não na manutenção das tradições culturais. Segundo Lévi-Strauss ${ }^{6}$, "Na América do Sul tropical, os níveis gerais de cultura são determinados antes por um critério histórico do que pelos recursos vegetais locais, uma vez que nenhuma característica cultural básica parece depender diretamente do ambiente botânico".

A distância entre população e costumes é um acontecimento cultural e não só geográfico, já que os bairros entrevistados se encontram em média, a três quilômetros de distância da Reserva. Isso indica que o conhecimento popular encontra-se confinado a um grupo de raizeiros ou "curadores", cuja atuação representa uma ponte cultural com as tradições medicinais de uso da flora local. 
Tabela 1. Plantas medicinais do cerrado, mais utilizadas pela população de Mossâmedes/GO

Nome científico/ vulgar

Alibertia sp. (Rubiaceae) / marmelo

Anacardium humile St. Hil. (Anacardiaceae) / cajuzinho

Anadenanthera falcata (Leguminosae) / angico

Anemopaegma arvense (Bignoniaceae) / catuaba

Anona crassiflora (Annonaceae) / araticum

Aristolochia sp. (Aristholochiaceae) / batata milhomem

Brosimum gaudichaudii Tréc. (Moraceae) / mamacadela

Bulbostylis capillaris L. C. B. Clark (Cyperaceae)

/ capim barba-de-bode

Calliandra dysantha Benth. (Leguminosae) / ciganinha

Cassia rugosa G. Don. (Leguminosae) / fedegoso-do-campo

Centrosema bracteosum (Fabaceae) / rabo-de-tatu

Clitoria guianensis Benth. (Leguminosae)/ vergateza

Coclospremum regium (Cochlospermaceae) / algodãozinho

Croton antisiphiliticus Mart. (Euphorbiaceae) / pé-de-perdiz

Curatella americana (Dilleniaceae) / lixeirinha

Dimorphandra mollis Benth. (Leguminosae) / fava d anta

Dypterix alata Vog. (Leguminosae) / barú

Eugenia dysenterica DC. (Myrtaceae) / cagaiteira

Gomphrena officinalis M. (Amaranthaceae) / paratudo

Hancornia speciosa Gomez. (Apocynaceae) / mangabeira

Heteropterys aphrodisiaca O. Mach. (Malpighiaceae)

/ nó-de-cachorro

Heterothalamus brunioides (Compositae) / alecrim-do-campo

Hymenaea stignocarpa Mart. ex. Hayne (Leguminosae) / jatobá

Ipomoea sp. (Convolvulaceae) / amaro-leite

Jacaranda decurrens (Bignoniaceae) / carobinha

Lafoensia pacari St. Hil. (Lytharaceae) / pacari

Lychnophora ericoidis Mart. (Apocynaceae) / arnica

Macrosiphonia velame (St. Hil.) M. Arg. (Apocynaceae)

/ velame-branco

Magonia pubenscens St. Hil. (Sapindaceae) / tingui

Mandevilla velutina (Apocynaceae) / batata infalível

Palicourea xantophylla Muell.Arg. (Rubiacea)/ douradinha

Psidium sp. (Myrtaceae) / goiabinha-do-campo

Pterodon pubescens Benth. (Leguminosae) / sucupira-branca

Qualea grandiflora (Vochysiaceae)/ pau terra

Renealmia exaltata L.f. (Zingiberaceae) / pacová

Rudgea virbunoides (Cham) Benth. (Rubiaceae)

/ congonha-de-bugre

Salvertia convallariodora St. Hil. (Vochysiaceae) / bate-caixa

Smilax brasiliensis Spreng (Smilacaceae)/ japecanga

Smilax sp. (Smilacaceae) / salsaparrilha

Solanum lycocarpum A. St. Hil. (Solanaceae) / lobeira Spiranthera odoratissima A. St. Hil. (Rutaceae)/ manacá

Stryphnodendron adstringens (Leguminosae) / barbatimão

Vellozia sp. (Velloziaceae) / canela-de-ema

Vernonia ferruginea (Compositae) / assapeixe-branco
Forma de utilização/ parte da planta utilizada

Decocção, infusão / raiz, fruto

Decocção / folha

Decocção / casca do caule

Infusão, decocção / raiz,

casca do caule, folha

Infusão / fruto, semente

Decocção / raiz

Decocção / raiz, casca do caule

Planta inteira

Decocção / raiz, flor

Decocção / folha, raiz

Infusão, decocção / raiz

Decoção, garrafada / raiz

Decocção / casca, raiz

Decoção, garrafada / raiz, folha

Infusão / folha e resina

Infusão / fruto verde

semente

Fruto fresco

Garrafada / raiz

Solução aquosa / látex

Garrafada / raiz, planta inteira

Infusão / folha

Decocção da casca do caule, resina, polpa do fruto

Decocção / raiz

Decoção, infusão / casca, raiz

Decocção / casca do caule, folha

Tintura / folhas

Infusão / folha e raiz, látex

Suco fresco / planta inteira

Decocção / raiz

Infusão / folha

Decocção / folha

Tintura / semente

Infusão / folha

Decocção, garrafada / raiz, folha,

casca do caule

Decoção, infusão / casca, raiz, folha

Decocção / folha

Decocção / raiz

Decocção / raiz

Polvilho / fruto

Decocção, infusão/ raiz, folhas

Decocção / casca do caule

Decocção / casca, raiz

Infusão / folhas, flor
Indicação terapêutica

Calmante

Inflamação ovariana

Afecções pulmonares

Esgotamento nervoso, impotência sexual, doença venérea

Anti-diarréico

Congestão, dor em geral

Depurativo, vitiligo, bronquite

Resfriado, febre alta

Regulador menstrual

Gripe, rouquidão, vermífugo

Afecções hepáticas

Estimulante, impotência sexual

Afecções urogenitais, purgativo

Anti-sifilítica, antiinflamatória,

antireumática

Adstringente, anti-séptico

Anti-hemorrágico

Reumatismo

Laxante

Febre, bronquite, depurativo, picada de cobra

Afecções pulmonares, caimbras

Impotência sexual, depurativo

estimulante coronariano

Depurativo, infecção, afecções

pulmonares

Depurativo do sangue

Infecções, reumatismo

Cicatrizante

Antiinflamatório

Úlcera, gastrite, doença venérea

Anti-séptico

Impotência sexual, depurativo

Depurativo, diurético

Anti-diarréico

Resfriado, infecções de garganta,

esquistossomose

Dores estomacais

Anti-helmintico, anti-reumático, carminativo

Anti-sifilítico, anti-reumático,

anemia

Hemorróida

Afecções do trato genital, eczema, reumatismo

Afecções do trato genital, eczema, reumatismo

Afecções hepáticas

Afecções estomacais e renais

Malária, anti-febrífugo, afecções

hepáticas

Anti-reumático, dores de coluna, afecções renais

Afecções pulmonares 


\section{Materiais e Métodos}

A coleta dos dados etnobotânicos para o desenvolvimento deste trabalho foi realizada por meio da aplicação de um questionário e entrevistas com os moradores de três conjuntos de habitações populares localizados em dois bairros da periferia da cidade com 100 residências visitadas, um bairro de localização central com 100 residências visitadas, e também com dois raizeiros residentes na cidade.

Totalizou-se um número de 200 pessoas, o que representa uma parcela de 5,5\% do total de habitantes da cidade, em faixa etária localizada entre 20 e 75 anos. A identificação e documentação das espécies levantadas foram realizadas na Reserva Biológica da Serra Dourada.

\section{Referências}

${ }^{1}$ Mendonça, R.C.; Felfini, J.M.; Walter, B.M.T. Flora vascular do cerrado. In: Sano, S.M.; Almeida, S.P. Cerrado, ambiente e flora. Planaltina: Embrapa/CAPC, p. 289-556, 1998.

${ }^{2}$ Camargo, M.T.L. A. medicina popular. Rio de Janeiro: Campanha de Defesa do Folclore Brasileiro, 46p., 1976.

${ }^{3}$ Amorozo, M.C.M. A abordagem etnobotânica na pesquisa de plantas medicinais. In: STASI, L.C. di (org.). Plantas medicinais: arte e ciência: um guia interdisciplinar, São Paulo: Editora da UNESP, p. 47-68, 1996.

${ }^{4}$ IBGE. Contagem da população de 1996. Rio de Janeiro, v.2. Resultados relativos à população e os domicílios, 1997.

${ }^{5}$ Mattos, R.J.C. Chorografia histórica da província de goyaz. Goiânia: IPHBC/Gráfica Editora Líder, 185p. 1979.

${ }^{6}$ Lévi-Strauss, C. O uso das plantas silvestres da América do Sul tropical. In: Ribeiro, B.G. (coord.). Suma etinológica brasileira. Etnobiologia, Petrópolis: Vozes, Finep., 2. ed., v. 1.p. 29-46, 1987.

*Autor para correspondência:

Profa. Giuliana Muniz Vila Verde

Faculdade de Farmácia - UFG

Praça Universitária com Primeira Avenida - Qd. 62 - s/n

Setor Universitário - CEP 74605-220 - Goiânia(GO)

E-mail: giulianavv@zipmail.com.br

\section{Monitoramento dos extratos brutos de espécies de Polygala (Polygalaceae) utilizando Artemia salina}

\author{
Montanher, A.B.P.; Pizzolatti, M.G.; Brighente, I.M.C.* \\ Laboratório de Química de Produtos Naturais, Departamento \\ de Química, Universidade Federal de Santa Catarina
}

Resumo

Extratos de duas espécies de Polygala foram submetidos a um biomonitoramento utilizando o teste de toxicidade frente a Artemia salina, com a finalidade de detectar atividade citotóxica. Os resultados obtidos para o extrato bruto, frações hexânica e diclorometano de Polygala sabulosa Aw. Benn. mostraram-se promissores. No entanto, bioensaios mais específicos devem ser encorajados nos extratos vegetais que apresentam atividade diante deste bioensaio, a fim de confirmar estas conclusões.

\begin{abstract}
Extracts of two species of Polygala were subjected to a bioscreening study to detect cytotoxic activity by the brine shrimp lethality bioassay. The results obtained for the crude extracts, hexanic and dichlorometane fractions of Polygala sabulosa Aw. Benn. were promising. These results suggest that in those plant extracts, which showed activity for this bioassay, more specific bioassays should be encouraged, in order to confirm these conclusions.
\end{abstract}

A obtenção de fármacos a partir de metabólitos secundários de origem vegetal, bem como o desenvolvimento de fitofármacos, vem despertando grande interesse não só por parte dos pesquisadores em produtos naturais, mas principalmente de pequenas e grandes indústrias farmacêuticas. Este fato requer uma rápida triagem dos compostos bioativos presentes em extratos de plantas através de procedimentos simples, rápidos e de baixo custo para que possam ser executados nos laboratórios de fitoquímica.

$\mathrm{O}$ teste de letalidade in vivo em organismos animais simples, tal como o teste de letalidade contra Artemia salina (TAS) desenvolvido por Meyer e colaboradores ${ }^{1}$, pode ser usado como um guia de triagem e fracionamento biomonitorado em extratos de plantas biologicamente ativos, onde a resposta mais simples para monitorar a letalidade é apenas um critério, vida ou morte $^{2}$. Este bioensaio correlaciona-se razoavelmente bem com citotoxicidade e outras propriedades biológicas ${ }^{2,3}$.

Este bioensaio vem sendo aplicado na avaliação de extratos de plantas usados na medicina tradicional ${ }^{4}$, em estudos etnofarmacológicos ${ }^{5}$, para detectar bioatividade de metabólicos de fungos patogênicos ${ }^{6}$ e de organismos marinhos ${ }^{7}$. A literatura 